\title{
Systematic Review of Escalated Imatinib Doses Compared with Sunitinib or Best Supportive Care, for the Treatment of People with Unresectable/Metastatic Gastrointestinal Stromal Tumours Whose Disease has Progressed on the Standard Imatinib Dose
}

\author{
Jennifer Hislop • Graham Mowatt • Pawana Sharma • \\ Cynthia Fraser • Andrew Elders • David Jenkinson • \\ Luke Vale $\cdot$ Russell Petty
}

Published online: 6 October 2011

(C) Queen's Printer and Controller of HMSO. 2011 All rights reserved. This article is published with open access at Springerlink.com

\begin{abstract}
Introduction We conducted a systematic review of evidence on the effectiveness of imatinib at escalated doses of $600 \mathrm{mg} /$ day or $800 \mathrm{mg} /$ day for treatment of adults with unresectable or metastatic gastrointestinal stromal tumours (GIST), following progression on imatinib at the $400 \mathrm{mg} / \mathrm{day}$ dose, compared with sunitinib and/or 'best supportive care'. Methods Electronic searches were undertaken to identify relevant randomised controlled trials (RCTs), non-randomised studies, and case series reporting outcome data on survival, quality of life or adverse events. Titles and abstracts were screened by two reviewers and full text reports of potentially relevant studies assessed for inclusion. Included studies were quality assessed by two reviewers and data were extracted. Five
\end{abstract}

J. Hislop $(\bowtie) \cdot$ G. Mowatt $\cdot$ P. Sharma $\cdot$ C. Fraser $\cdot$ A. Elders $\cdot$ D. Jenkinson $\cdot$ L. Vale

Health Services Research Unit (HSRU), Institute of Applied

Health Sciences, University of Aberdeen,

3rd Floor, Health Sciences Building, Foresterhill,

Aberdeen AB25 2ZD, UK

e-mail: j.hislop@abdn.ac.uk

L. Vale

Health Economics Research Unit (HERU), Institute of Applied

Health Sciences, University of Aberdeen,

Polwarth Building, Foresterhill,

Aberdeen AB25 2ZD, UK

\section{R. Petty}

Division of Applied Medicine, School of Medicine and Dentistry, University of Aberdeen and Aberdeen Royal Infirmary,

NHS Grampian, Foresterhill,

Aberdeen AB25 2ZD, UK studies reported data on the relevant population and were included.

Results and Discussion Median overall survival for imatinib ( $800 \mathrm{mg} /$ day) and sunitinib both were less than 2 years. Around $25 \%$ of patients required either an imatinib dose delay or reduction. Approximately one-third of patients receiving dose escalated imatinib (either dose) showed either response or stable disease. Amongst those responding to the escalated $800 \mathrm{mg} /$ day dose, median progression-free survival was over 25 months. The statistical likelihood of response may depend on exon mutational status. There were few data and those that were available were potentially biased, due to their non-randomised nature. Further data are needed to justify international guideline recommendations on imatinib dose escalation.

Conclusion A prospective audit of management and outcomes for unresectable GIST patients treated with dose escalation upon progression at $400 \mathrm{mg} /$ day may be appropriate as an RCT may be unfeasible.

Keywords GIST - Gastrointestinal stromal tumours · Unresectable $\cdot$ Metastatic $\cdot$ Cancer $\cdot$ Imatinib $\cdot$ Sunitinib

\section{Introduction}

Gastrointestinal stromal tumours (GISTs) are a rare malignancy, accounting for less than $1 \%$ of all cancers of the gastrointestinal (GI) tract [1] and in Europe the annual incidence is 15 cases per million population [2]. They are a distinct tumour type arising from the interstitial cells of 
Cajal (ICC), characterised in $96 \%$ of cases by the expression of the receptor tyrosine kinase KIT (CD117) protein (demonstrable on immunohistochemistry) [3]. The $4 \%$ of GIST cases that are KIT negative $[4,5]$ are more likely to contain platelet-derived growth factor receptor alpha (PDGFRA) mutations [4], and this and alternative markers (e.g. DOG1) can be used to enable diagnosis if KIT immunochemistry is negative [2].

Within the past decade, imatinib (at doses of 400 to $800 \mathrm{mg}$ /day) and sunitinib have been licensed for the treatment of GIST. Prior to this, 'best supportive care' (e.g. to control symptoms and pain) was the only available treatment for those with unresectable disease. The prognosis for this patient group was poor, with few patients surviving 2 years $[6,7]$.

Management of unresectable and/or metastatic GIST typically involves commencing patients on the standard imatinib dose of $400 \mathrm{mg} / \mathrm{day}$. On confirmed disease progression at this dose, decisions regarding treatment depend on the individual's clinical circumstances, but options can include dose escalation of imatinib up to an $800 \mathrm{mg} /$ day dose, sunitinib (within its licensed dose range) or best supportive care [3, 8-10].

Response to imatinib is more likely in GISTs with certain pathogenic KIT mutations. This could provide predictive biomarkers to enable the personalisation and optimisation of first- and second-line therapy [11]. In a recent meta-analysis of RCTs comparing first-line use of standard $400 \mathrm{mg} /$ day imatinib with an initial $800 \mathrm{mg} /$ day dose, those with exon nine mutations had longer progression-free survival $(p=0.017)$, but not overall survival $(p=0.150)$ in the $800 \mathrm{mg} /$ day arm. This suggests the possibility that patients with exon 9 mutations may benefit from immediate high dose imatinib treatment, as opposed to escalation only upon disease progression [12].

However, even if individually tailored imatinib starting doses, based on the identification of KIT mutations (or other biomarkers), become standard clinical practice in future, evidence on the effectiveness of escalated imatinib doses in unresectable or metastatic disease following progression on the $400 \mathrm{mg} /$ day dose is still relevant. This is because all patients eventually progress after an initial response and for those on $400 \mathrm{mg} /$ day, dose escalation remains an available option [13-17]. Some of the clinically relevant molecular mechanisms for secondary resistance to imatinib $400 \mathrm{mg}$ /day have also recently been identified, and secondary mutations in KIT exons 13, 14, 17, and 18 are associated with acquired resistance to imatinib [15], which may also impact on the effectiveness of imatinib dose escalation.

The objective of this review was to determine the relative benefit (in patients who have acquired resistance to the $400 \mathrm{mg} /$ day imatinib dose) of dose escalation (to either $600 \mathrm{mg} /$ day or $800 \mathrm{mg} /$ day imatinib), sunitinib or best supportive care.

\section{Materials and Methods}

Electronic searches of relevant databases were undertaken to identify reports of published and ongoing studies. The searches were designed to be sensitive, using both controlled vocabulary and text terms. Full details of the search strategies used can be obtained from the authors. The databases searched were: Medline (1966-September Wk 3 2009), Medline In-Process (25th September 2009), Embase (1980-Week 39 2009), CINAHL (September 2009), Science Citation Index (2000-26th September 2009), Biosis (2000 - 24th September 2009), Health Management Information Consortium (September 2009), and the Cochrane Controlled Trials Register for primary research and the Database of Abstracts of Reviews of Effects (DARE) (October 2009), the Cochrane Database of Systematic Reviews (CDSR; Issue 3 2009) and the HTA database for relevant evidence syntheses (October 2009).

Ongoing and recently completed trials were identified from current research registers, including Clinical Trials, Current Controlled Trials, NIHR Portfolio, WHO International Clinical Trials Registry Platform, IFPMA Clinical Trials and the ABPI database. Recent conference proceedings of key oncology and gastrointestinal organisations, including the American Society for Clinical Oncology (ASCO), European Society for Medical Oncology (ESMO) and the European Cancer Organisation were also searched. Websites of the GIST Support International, and the drug manufacturers, Pfizer (sunitinib) and Novartis (imatinib), were also scrutinised as were the reference lists of retrieved papers, in order to identify additional potentially relevant studies.

Randomised controlled trials (RCTs), non-randomised comparative studies and case series were all considered relevant and non-English language studies were permitted. Studies of animal models, preclinical and biological studies, reviews, editorials, opinions, case reports and reports investigating technical aspects of the interventions were excluded.

The population of interest was adults with KIT-positive unresectable and/or metastatic gastrointestinal stromal tumours (GIST), whose disease had progressed on treatment with imatinib on $400 \mathrm{mg} /$ day. Subgroup analysis was to be undertaken (if data were available) on patients with differing KIT mutations.

The interventions under consideration were imatinib at escalated doses of $600 \mathrm{mg} /$ day or $800 \mathrm{mg} /$ day, being prescribed in addition to best supportive care, which was defined to include active symptom control, pain management and "the multi-professional attention to the individual's overall physical, psychosocial, spiritual and cultural needs" [18]. The comparators considered were sunitinib (prescribed within its recommended dose range of $25-75 \mathrm{mg} /$ day and provided in addition to best supportive care), and best supportive care alone. 
Included studies were required to report at least one of the following outcomes: overall response, overall survival, disease-free survival, progression-free survival, time to treatment failure, health-related quality of life or the adverse effects of treatment.

Two reviewers independently screened titles and abstracts of all records identified by the searches and assessed full-text copies of all potentially relevant reports against the predefined inclusion criteria. Screening and data extraction forms were developed to assist in obtaining relevant information. Data extraction was undertaken by two reviewers; dual data extraction was not conducted but both reviewers were trained in data extraction and therefore inter-rater reliability was expected to be good [19].

Two reviewers also independently assessed the methodological quality of the included full-text studies, utilising an 18question checklist that was adapted from several sources [2022]. Included conference abstracts were not quality assessed because they were considered unlikely to provide sufficient methodological information to enable an accurate assessment of study quality.

All disagreements between reviewers during screening and quality assessment were resolved by discussion and consensus. No arbitration by a third party was necessary.

Data analysis methods for circumstances where sufficient evidence for quantitative synthesis were available was initially planned but where this was not considered feasible (e.g. due to insufficient available evidence) a narrative synthesis of results was conducted.

\section{Results}

Search Results and Studies Included

A flow diagram of the search results and screening process is outlined in Fig. 1. Six full-text papers [13, 17, 23-26] and ten abstracts [27-36] reporting the results of four trials and one additional retrospective cohort, met our inclusion criteria. The main reason for the exclusion of full-text papers not meeting the review inclusion criteria are provided in Table 1.

Corresponding authors were contacted for nine studies (reported in a total of 14 papers) to clarify and determine study inclusion or exclusion. Four authors (28.6\%) responded. In three instances the studies were excluded (personal communication, P Rutkowski and P Wolter, Jan 2010) and in one instance [26], the study was included. It was necessary to exclude the remaining ten papers, as clarification was not provided [37-41].

No RCTs or non-randomised comparative studies were found that directly compared the effectiveness of imatinib at escalated doses (600 or $800 \mathrm{mg}$ /day) with either sunitinib or best supportive care. One on-going trial comparing an escalated imatinib dose with sunitinib was identified, but this trial had been stopped due to poor recruitment [42].

Relevant data were reported in five full-text reports of three RCTs. These were:

- EORTC-ISG-AGITG (62005) trial, as reported by Zalcberg and colleagues [17] and Debiec-Rychter and colleagues [24], with one additional abstract reporting interim data [36].

- S0033 trial as reported by Blanke and colleagues [13], with two additional abstracts reporting interim data $[27,29]$.

- B2222 trial as reported by Blanke and colleagues [23], and Demetri and colleagues [43].

Each trial compared randomisation to $400 \mathrm{mg} / \mathrm{day}$ imatinib with randomisation to a high (e.g. $600 \mathrm{mg} /$ day or $800 \mathrm{mg} /$ day) dose. Each of these papers reported separate data on the outcomes of patients initially randomised to $400 \mathrm{mg}$ /day who went on to receive an escalated dose only upon progression at this dose. As these participants were randomised to the $400 \mathrm{mg} / \mathrm{day}$ arm but were not further randomised to an escalated dose on progression, the data
Fig. 1 Flow diagram outlining the screening process for the review of clinical effectiveness
3366 titles and abstracts identified from primary searches

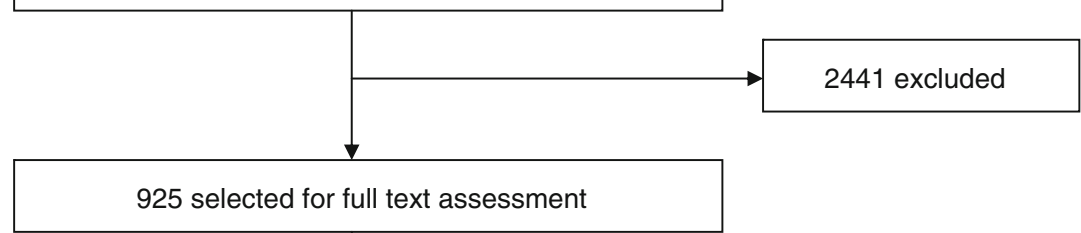

909 articles excluded (see Table 1 for reasons for exclusion) 
Table 1 Reasons for exclusion of studies

\begin{tabular}{lc}
\hline Reason for exclusion & $\begin{array}{l}\text { Number of } \\
\text { studies } \\
\text { excluded }\end{array}$ \\
\hline Patient had resectable GIST & 24 \\
Outcomes not reported separately for GIST & 10 \\
patients & 46 \\
$<10$ patients in relevant study population & 13 \\
Imatinib dose is 400 mg/day & 66 \\
No/insufficient data reported for escalated & 84 \\
dose patients & 15 \\
No imatinib dose reported & 11 \\
No relevant interventions & 10 \\
Treatment not evaluated & 61 \\
No outcomes of relevance & 340 \\
Other reason & 49 \\
& 169 \\
Retained for background information & 117 \\
Review articles & 64 \\
Letter/editorial/correspondence/symposium & 123 \\
articles/meeting reports/expert views/comments & 47 \\
Case study/case series $<10$ patients & 909 \\
Non-English language exclusions & \\
Not obtained & \\
Total & \\
\hline
\end{tabular}

are essentially observational even though they are derived from RCTs.
The escalated dose for the EORTC-ISG-AGITG and S0033 trials was $800 \mathrm{mg} /$ day [13, 17], while for the B2222 trial it was $600 \mathrm{mg} /$ day [23].

In addition, one full-text paper of a non-randomised retrospective study by Park and colleagues, was also included, as it contained data on two groups of patients receiving each of the escalated doses upon progression at $400 \mathrm{mg} /$ day [26].

For sunitinib, seven abstracts met the inclusion criteria [28, 30-35]. All related to an on-going, open-label sunitinib trial reporting information on participants recruited to the trial following failure at a variety of different doses of imatinib, and reported separate information for a prior imatinib dose of $\leq 400 \mathrm{mg} /$ day. The abstract by Seddon and colleagues [35] was considered the most recent and therefore designated the primary report for this study.

Corresponding authors of each included trial were contacted to determine whether any additional data could be provided for the relevant study population within the timeframe of this review. Data for the S0033 trial were provided by the authors (personal communication, $\mathrm{C}$ Rankin, February 2010).

Data were extracted for all outcomes of interest. No study reported data on disease-free survival or healthrelated quality of life. Baseline characteristics for the relevant study population (i.e. those who received escalated imatinib doses) were reported in two studies [17, 26].

Results of the quality assessment are provided in Fig. 2. Study quality was similar for all imatinib studies, though

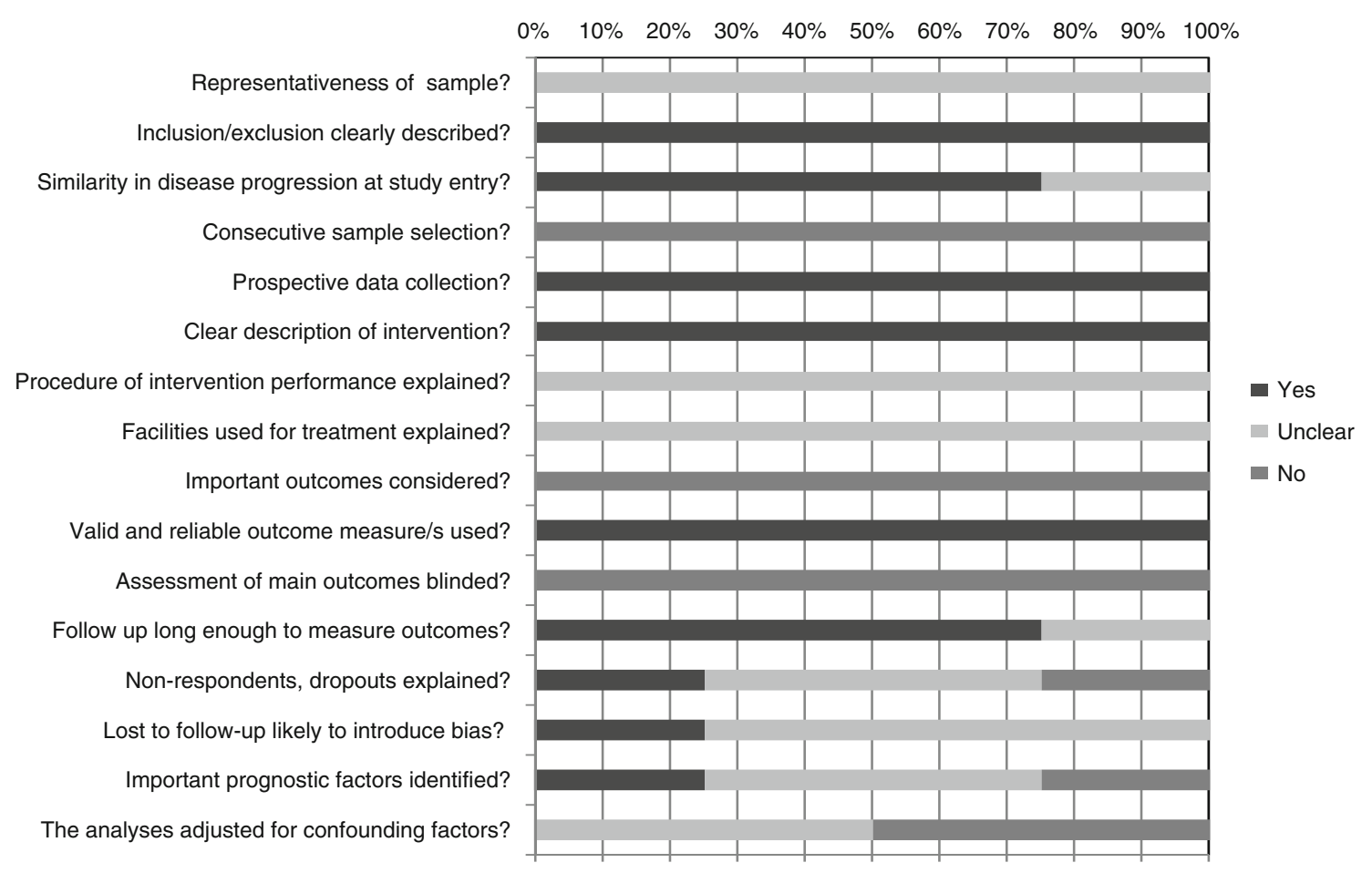

Fig. 2 Quality assessment of included full-text papers 
assessment was complicated as the population of interest was a subgroup within each trial and therefore data were observational. None of the studies had a consecutive sample selection, had considered all the important outcomes of relevance or blinded outcome assessment, or had clearly adjusted for confounding factors. However, all had used valid and reliable outcome measures, described inclusion and exclusion criteria, and the interventions clearly and had collected data prospectively. Assessment with the remaining quality criteria was unclear for all studies or varied between studies.

Clinical Outcome Results for Dose Escalation of Imatinib or Sunitinib

Outcome results reported for each of the included imatinib studies are provided in Table 2. Additional data on specific adverse events were provided for the relevant study population only for the EORTC-ISG-AGITG trial [17]. Following dose escalation to $800 \mathrm{mg} /$ day, a significantly lower rate of neutropenia was observed $(p=0.002)$. However, among the same population, significantly higher rates of anaemia and fatigue ( $p=0.015$ and $p<0.001$, respectively) were observed [17].

With regard to mutational analysis, Debiec-Rychter and colleagues in secondary analysis for the EORTC-ISGAGITG trial demonstrated that response following dose escalation was significantly more likely to occur in patients with wild-type KIT GISTs compared with those with KIT exon 11 mutations $(p=0.0012)$, and was also significantly more likely to occur in patients with KIT exon 9 mutations compared with KIT exon 11 mutations ( $p=0.0017$ ), though no figures were reported for the number of patients involved [24].

For sunitinib, overall survival was reported by Seddon and colleagues as being 90 weeks (95\% CI 73 to 106 weeks)

Table 2 Results from included imatinib studies

\begin{tabular}{|c|c|c|c|c|c|}
\hline \multirow{2}{*}{$\begin{array}{l}\text { Drug (dose) } \\
\text { Study }\end{array}$} & \multicolumn{2}{|c|}{ Imatinib (600 mg/day) } & \multicolumn{3}{|c|}{ Imatinib (800 mg/day) } \\
\hline & Park et al. [26] & $\mathrm{B} 2222$ [23] & Park et al. [26] & S0033 [13] & $\begin{array}{l}\text { EORTC-ISG- } \\
\text { AGITG [17] }\end{array}$ \\
\hline $\begin{array}{l}\text { Number receiving } \\
\text { escalated dose }\end{array}$ & 12 & 43 & 12 & 118 & 133 \\
\hline Median follow up (range) & $\begin{array}{l}8 \text { months ( } 1.4 \text { to } \\
22.3 \text { months) }\end{array}$ & $\begin{array}{l}63 \text { months } \\
\text { (NR-71 months) }\end{array}$ & $\begin{array}{l}8 \text { months ( } 1.4 \text { to } \\
22.3 \text { months) }\end{array}$ & 54 months (NR) & $\begin{array}{l}25 \text { months } \\
\text { (NR to } \\
35 \text { months) }\end{array}$ \\
\hline $\mathrm{N}(\%)$ with response & NR & NR & NR & $3 / 117(2.6 \%)$ & $3 / 133(2.3 \%)$ \\
\hline $\mathrm{N}(\%)$ with stable disease & NR & NR & NR & $33 / 117(28.2 \%)$ & $36 / 133(27.0 \%)$ \\
\hline $\begin{array}{l}\text { Total N(\%) with response } \\
\text { or stable disease }\end{array}$ & $5 / 12(41.7 \%)$ & $11 / 43(25.6 \%)^{\mathrm{b}}$ & $4 / 12(33.3 \%)$ & $36 / 117(30.8 \%)$ & $39 / 133(29.3 \%)$ \\
\hline $\begin{array}{l}\text { Median overall } \\
\text { survival }(95 \% \mathrm{CI})^{\mathrm{a}}\end{array}$ & NR & NR & NR & $\begin{array}{l}19 \text { months ( } 13 \text { to } \\
23 \text { months) }\end{array}$ & NR \\
\hline $\mathrm{N}(\%)$ still alive & NR & NR & NR & $42 / 118(35.6 \%)$ & NR \\
\hline $\begin{array}{l}\text { Progression-free } \\
\text { survival }(95 \% \mathrm{CI})^{\mathrm{a}}\end{array}$ & NR & NR & NR & $\begin{array}{l}5 \text { months ( } 2 \text { to } \\
10 \text { months })\end{array}$ & $\begin{array}{l}2.9 \text { months } \\
\text { (not reported) }\end{array}$ \\
\hline $\mathrm{N}(\%)$ progression free & NR & NR & NR & $19 / 118(16.1 \%)$ & $25 / 133(18.8 \%)$ \\
\hline $\begin{array}{l}\text { Median duration of } \\
\text { "stabilisation"/time to } \\
\text { progression }\end{array}$ & $\begin{array}{l}1.7 \text { months } \\
\text { (range: } 0.7 \text { to } \\
24.9 \text { months) }\end{array}$ & NR & NR & NR & $\begin{array}{l}5.5 \text { months } \\
\quad \text { (range: } 1.3 \text { to } \\
20.5 \text { months) }\end{array}$ \\
\hline Disease free survival & NR & NR & NR & NR & NR \\
\hline $\begin{array}{l}\text { Health related quality } \\
\text { of life }\end{array}$ & NR & NR & NR & NR & NR \\
\hline $\begin{array}{l}\mathrm{N}(\%) \text { discontinuations } \\
\text { due to adverse events }\end{array}$ & NR & NR & NR & NR & $11 / 97(11.6 \%)^{\mathrm{c}}$ \\
\hline $\mathrm{N}(\%)$ with $\geq 1$ dose delay & NR & NR & NR & $18 / 77(23.3 \%)$ & NR \\
\hline $\begin{array}{l}\mathrm{N}(\%) \text { with } \geq 1 \text { dose } \\
\text { reduction }\end{array}$ & NR & NR & NR & $12 / 77(15.6 \%)$ & NR (31\%) \\
\hline
\end{tabular}

$N R$ not reported

${ }^{\text {a }}$ Unless explicitly stated to be a reported range

${ }^{\mathrm{b}}$ One patient only achieved response/stable disease following further dose escalation to $800 \mathrm{mg}$ /day

${ }^{\mathrm{c}}$ Figure estimated from data reported in the paper

${ }^{\mathrm{d}}$ Unit of measurements has been converted to months by dividing by 28 (for days), dividing by 4 (weeks), or multiplying by 12 (years) 
for those receiving sunitinib upon progression with an imatinib dose of $\leq 400 \mathrm{mg} /$ day. However, the median follow up time (51 weeks, 95\% CI 0.1 to 159 weeks) was only available for the entire study population (i.e. regardless of prior imatinib dose). Of those receiving sunitinib after progression on the $\leq 400 \mathrm{mg}$ /day imatinib dose 193/351 (55\%) were still alive at the time of analysis [35].

Overall survival with the escalated $800 \mathrm{mg} /$ day dose of imatinib was compared with sunitinib at a dose of $50 \mathrm{mg}$ for patients who had progressed on imatinib at a dose of $\leq 400 \mathrm{mg} /$ day using data for the S0033 trial provided by authors, and quarterly overall survival estimates reported in a Kaplan-Meier chart by Seddon and colleagues, employing the method proposed by Parmar and colleagues [44] (Fig. 3). A meta-analysis of available Kaplan-Meier data for progression-free survival for the EORTC-ISG-AGITG and S0033 trials of the escalated $800 \mathrm{mg} /$ day imatinib dose was attempted using the method described by Arends and colleagues [45], but was not possible due to lack of data. A visual description of the progression-free survival results from these studies is provided in Fig. 4.

\section{Discussion}

This systematic review was performed to address the question: "What is the most effective management strategy for patients with advanced GISTs who have progressed following initial therapy with imatinib $400 \mathrm{mg} /$ day?" Dose escalation of imatinib, sunitinib, and best supportive care were the options considered. The review of the evidence base was detailed and thorough, and a large number of full-text papers were assessed against the inclusion criteria. Non-English language studies were reviewed, and attempts were made to contact study authors for clarification and additional data.

The data show that following dose escalation of imatinib, approximately one-third of patients achieved a partial response or stable disease. Over a median follow-up of over 2 years, more than half (i.e. $44 / 75$ or $58.7 \%$ ) of those who showed response or stable disease on the $800 \mathrm{mg} /$ day escalated dose remained progression free. Dose escalation appeared to be well tolerated, for most patients, although more fatigue and myelosuppression were observed.

Overall survival was less than 2 years for both those receiving the $800 \mathrm{mg} /$ day imatinib dose and those receiving sunitinib. However, given the nature of the evidence base it is difficult to draw any conclusions regarding possible differences in survival between treatments.

One possible explanation for the guidance advocating dose escalation so widely is the extent of the anecdotal evidence for its effectiveness in clinical practice and the evidence (observed disease control rates of $30 \%$ with $59 \%$ of these patients remaining progression free for over 2 years after dose escalation) supports this. Another explanation is that the effectiveness of high dose imatinib as an initial treatment is assumed to also apply to escalated dosing (which may not be clinically or biologically valid). Within our study these data on initial high imatinib dosing were

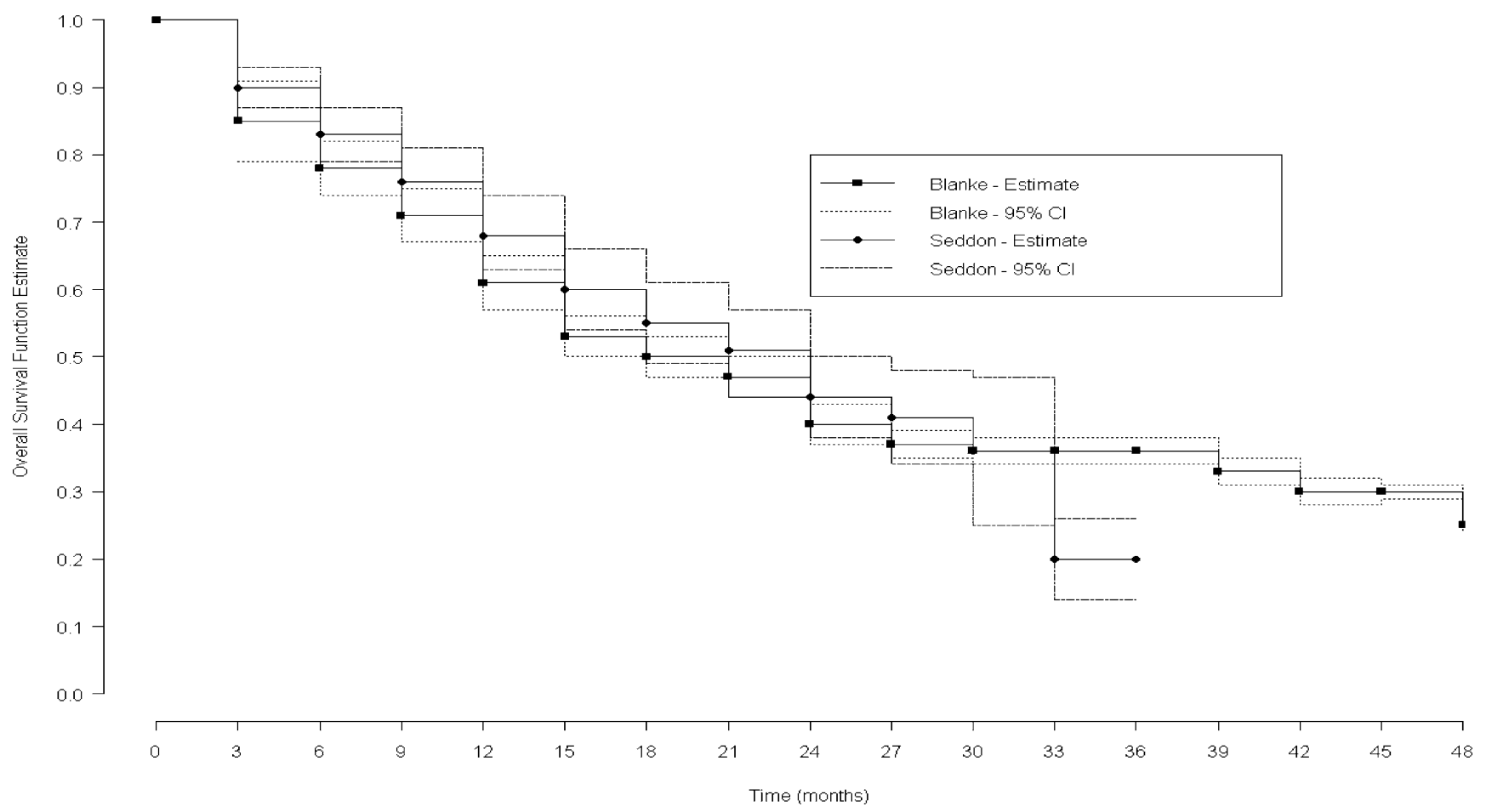

Fig. 3 Comparison of overall survival estimates for imatinib at $800 \mathrm{mg} /$ day [13] and sunitinib at $50 \mathrm{mg}$ [34] 


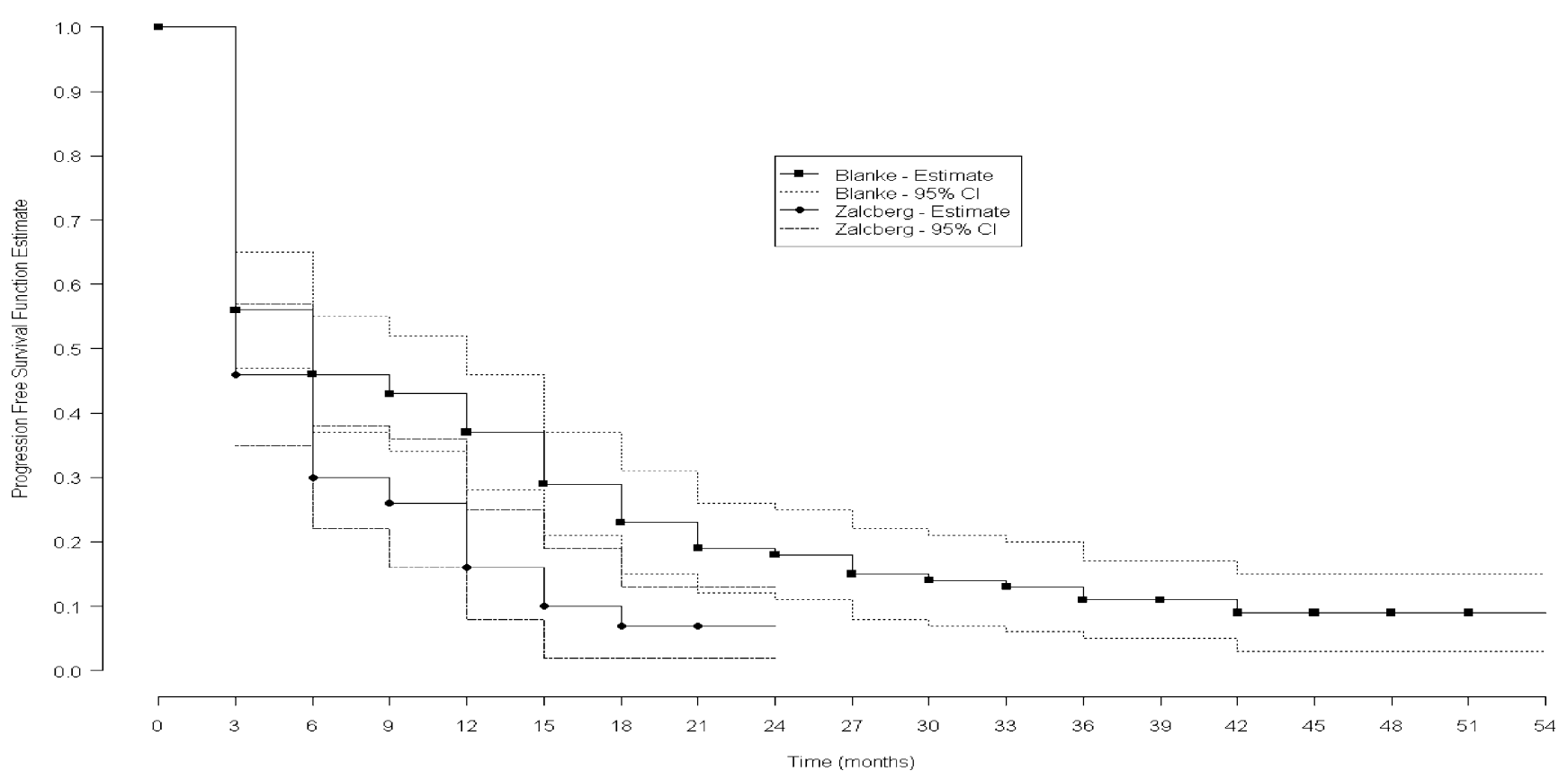

Fig. 4 Comparison between two studies of progression free survival estimates with imatinib at $800 \mathrm{mg} /$ day $[13,17]$

excluded because this represents a clinically and biologically distinct model from dose escalation upon progression, especially in terms of distinct mechanisms for primary or acquired resistance to high dose imatinib. It would not be valid to assume that these mechanisms would be the same for those receiving high-dose imatinib initially, as for those patients who receive initial $400 \mathrm{mg}$ dosing, become resistant, and are subjected to dose escalation at that point.

Clinical practice may be changing to enable mutational status to be used to tailor a patient's initial imatinib dose in future. With regard to imatinib dose escalation, the mutational status of the $16(600 \mathrm{mg} /$ day $)$ and 75 patients $(800 \mathrm{mg} /$ day $)$ showing response or stable disease with escalated imatinib doses in this review was not known. Evidence of the effectiveness of imatinib dose-escalation on these patient subgroups therefore remains lacking, although the EORTC-ISG-AGITG trial results reported (using $p$ values only) that wild-type KIT and exon nine mutations were significantly more likely to respond to escalated doses compared with those with exon 11 mutations [24]. Even if clinical practice changes to recommend patients with exon nine or wild-type KIT receive high doses of imatinib from commencement of treatment rather than on progression at the standard dose, evidence on the effectiveness of dose escalated imatinib will still be necessary for patients who do not have these particular mutations.

\section{Limitations}

The non-randomised, observational nature of the available data is prone to a range of biases (e.g. confounding). In addition, none of the studies distinguished between whether participants had shown progression or whether they had shown intolerance to imatinib at $400 \mathrm{mg} /$ day. For the included sunitinib trial it was necessary to assume that the majority of the participants receiving " $\leq 400 \mathrm{mg} /$ day" had received the actual dose of $400 \mathrm{mg} /$ day, rather than lower doses. No 'offlicence' treatments for GIST were considered (e.g. doses exceeding $800 \mathrm{mg} /$ day or continuous daily dosing of sunitinib). Surgical interventions were also not considered, even though they may offer an important treatment option (e.g. in emergencies as part of best supportive care, or if drug treatment shrinks tumours sufficiently to enable resection).

\section{Conclusions and Recommendations}

This review demonstrates that although dose escalation is widely recommended within clinical guidance documents [8-10], the actual evidence for its effectiveness among the unresectable and/or metastatic GIST population after progression at the standard $400 \mathrm{mg} /$ day imatinib dose is based solely on the results of several sets of observational data reported within wider RCT evidence on the effectiveness of standard versus high doses of imatinib.

Ideally, the existing evidence base could be improved with new RCT evidence, but this is unlikely to be feasible or appropriate given both the low incidence and the nature of the disease. However, well-designed, non-randomised studies could potentially help guide policy development on treatment for this population group.

Imatinib and sunitinib trialists with access to existing evidence on dose escalation outcomes (particularly for 
patients of differing mutational status) should consider publishing these data separately if this has not already been done, or attempt to pool existing patient-level data. Sixtysix studies were excluded from this review because they had not reported any separate information for dose escalated patients, and a further 84 studies were excluded because they did not report any information on imatinib dose (including sunitinib studies not reporting information on the prior imatinib dose received by the study population). It is therefore possible that pooling any existing unpublished patient level data could help clarify the comparative effectiveness of dose escalation upon progression on the $400 \mathrm{mg} /$ day imatinib dose.

Acknowledgments We thank the study authors we contacted who provided additional details of their studies, Cathryn Rankin (Southwest Oncology Group) for providing additional data from the S0033 trial, Lara Kemp (Health Services Research Unit) for secretarial support and Zahidul Quayyum (Health Economics Research Unit) for contributing his advice during the development of the review.

Conflicts of Interest statement None declared.

Sources of support This project was funded by the National Institute for Health Research Health Technology Assessment (NIHR HTA) programme and commissioned on behalf of the National Institute for Health and Clinical Excellence (NICE). It will be published in full in the Health Technology Assessment journal series. Visit the HTA programme website for more details www.hta.ac.uk/ 2154. The views and opinions expressed therein are those of the authors and do not necessarily reflect those of the HTA programme, NICE, NIHR, NHS or the Department of Health. The Health Services Research Unit, and Health Economics Research Unit, Institute of Applied Health Sciences, University of Aberdeen are both corefunded by the Chief Scientist Office (CSO) of the Scottish Government Health Directorates. The views expressed are those of the authors and not necessarily those of the funding bodies.

Open Access This article is distributed under the terms of the Creative Commons Attribution Noncommercial License which permits any noncommercial use, distribution, and reproduction in any medium, provided the original author(s) and source are credited.

\section{References}

1. Graadt van Roggen JF, van Velthuysen ML, Hogendoorn PC. The histopathological differential diagnosis of gastrointestinal stromal tumours. J Clin Pathol. 2001;54:96-102.

2. Guidelines for the management of gastrointestinal stromal tumours (GISTS) in Scotland. Glasgow: Scottish Sarcoma Network; 2009 [accessed December 2010]. URL: http://www.ssn. scot.nhs.uk/protocolsandguidelines/Scottish\%20GIST\%20guide lines NOV545 no\%.

3. Kindblom LG, Remotti HE, Aldenborg F, Meis-Kindblom JM. Gastrointestinal pacemaker cell tumor (GIPACT): gastrointestinal stromal tumors show phenotypic characteristics of the interstitial cells of Cajal. Am J Pathol. 1998;152:1259-69.
4. Medeiros F, Corless CL, Duensing A, Hornick JL, Oliveira AM, Heinrich MC, et al. KIT-negative gastrointestinal stromal tumors: proof of concept and therapeutic implications. Am J Surg Pathol. 2004;28:889-94.

5. Miettinen M, Majidi M, Lasota J. Pathology and diagnostic criteria of gastrointestinal stromal tumors (GISTs): a review. Eur J Cancer. 2002;38:S39-51.

6. Conlon KC, Casper ES, Brennan MF. Primary gastrointestinal sarcomas: analysis of prognostic variables. Ann Surg Oncol. 1995;2:26-31.

7. Dematteo RP, Lewis JJ, Leung D, Mudan SS, Woodruff JM, Brennan MF. Two hundred gastrointestinal stromal tumors: recurrence patterns and prognostic factors for survival. Ann Surg. 2000;231:51-8.

8. Casali P, Blay JY. Gastrointestinal stromal tumours. ESMO clinical practice guidelines for diagnosis, treatment and followup. Ann Oncol. 2010;21:v98-v102.

9. Guidelines for the management of gastrointestinal stromal tumours (GISTS). London: Association of Upper Gastrointestinal Surgeons of Great Britian and Ireland; 2005 [accessed February 2011]. URL: http://www.augis.org/news_guidelines/management_ guidelines.htm.

10. Demetri GD, von MM, Antonescu CR, Dematteo RP, Ganjoo KN, Maki RG, et al. NCCN Task Force report: update on the management of patients with gastrointestinal stromal tumors. $J$ Natl Comp Cancer Network 2010;8:Suppl-41.

11. Alymani NA, Smith MD, Williams DJ, Petty RD. Predictive biomarkers for personalised anti-cancer drug use: discovery to clinical implementation. Eur J Cancer. 2010;46:869-79.

12. Gastrointestinal Stromal Tumor Meta-Analysis Group. Comparison of two doses of imatinib for the treatment of unresectable or metastatic gastrointestinal stromal tumors: a meta-analysis of 1,640 patients. J Clin Oncol. 2010;28:1247-53.

13. Blanke CD, Rankin C, Demetri GD, Ryan CW, von Mehren M, Benjamin RS, et al. Phase III randomized, intergroup trial assessing imatinib mesylate at two dose levels in patients with unresectable or metastatic gastrointestinal stromal tumors expressing the kit receptor tyrosine kinase: S0033. J Clin Oncol. 2008;26:626-32.

14. Blay JY, Le Cesne A, Ray-Coquard I, Bui B, Duffaud F, Delbaldo $\mathrm{C}$, et al. Prospective multicentric randomized phase III study of imatinib in patients with advanced gastrointestinal stromal tumors comparing interruption versus continuation of treatment beyond 1 year: the French Sarcoma Group. J Clin Oncol. 2007;25:110713.

15. Gramza AW, Corless CL, Heinrich MC. Resistance to tyrosine kinase inhibitors in gastrointestinal stromal tumors. Clin Cancer Res. 2009;15:7510-8.

16. Verweij J, Casali PG, Zalcberg J, LeCesne A, Reichardt P, Blay JY, et al. Progression-free survival in gastrointestinal stromal tumours with high-dose imatinib: randomised trial. Lancet. 2004;364:1127-34.

17. Zalcberg JR, Verweij J, Casali PG, Le Cesne A, Reichardt P, Blay JY, et al. Outcome of patients with advanced gastro-intestinal stromal tumours crossing over to a daily imatinib dose of $800 \mathrm{mg}$ after progression on $400 \mathrm{mg}$. Eur J Cancer. 2005;41:1751-7.

18. Ahmed N, Ahmedzai S, Vora V, Hillam S, Paz A. Supportive care for patients with gastrointestinal cancer. Cochrane Database Syst Rev. 2004. doi:10.1002/14651858.CD003445.pub2. Art. No.: CD003445.

19. Haywood KL, Hargreaves J, White R, Lamb SE. Reviewing measures of outcome: reliability of data extraction. J Eval Clin Pract. 2004;10:329-37.

20. Systematic reviews: CRD's guidance for undertaking systematic reviews in health care [document on the Internet]. University of York: Centre for Reviews and Dissemination; 2009 [accessed 
January 2011]. URL: http://www.york.ac.uk/inst/crd/SysRev/! SSL!/WebHelp/SysRev3.htm.

21. Downs SH, Black N. The feasibility of creating a checklist for the assessment of the methodological quality both of randomised and non-randomised studies of health care interventions. J Epidemiol Community Health. 1998;52:377-84.

22. Verhagen AP, de Vet HC, de Bie RA, Kessels AG, Boers M, Bouter LM, et al. The Delphi list: a criteria list for quality assessment of randomized clinical trials for conducting systematic reviews developed by Delphi consensus. J Clin Epidemiol. 1998;51:1235-41.

23. Blanke CD, Demetri GD, von Mehren M, Heinrich MC, Eisenberg B, Fletcher JA, et al. Long-term results from a randomized phase II trial of standard-versus higher-dose imatinib mesylate for patients with unresectable or metastatic gastrointestinal stromal tumors expressing KIT. J Clin Oncol. 2008;26:620-5.

24. Debiec-Rychter M, Sciot R, Le Cesne A, Schlemmer M, Hohenberger P, Van Oosterom AT, et al. KIT mutations and dose selection for imatinib in patients with advanced gastrointestinal stromal tumours. Eur J Cancer. 2006;42:1093-103.

25. Demetri GD, von Mehren M, Blanke CD, Van den Abbeele AD, Eisenberg B, Roberts PJ, et al. Efficacy and safety of imatinib mesylate in advanced gastrointestinal stromal tumors. N Engl J Med. 2002;347:472-80.

26. Park I, Ryu MH, Sym SJ, Lee SS, Jang G, Kim TW, et al. Dose escalation of imatinib after failure of standard dose in Korean patients with metastatic or unresectable gastrointestinal stromal tumor. Jpn J Clin Oncol. 2009;39:105-10.

27. Dileo P, Rankin CJ, Benjamin RS, von Mehren M, Blanke C, Bramwell $\mathrm{V}$, et al. Incidence and reasons for dose modification of standard-dose vs. high-dose imatinib mesylate (IM) in the Phase III Intergroup Study S0033 of patients (pts) with unresectable or metastatic gastrointestinal stromal tumor (GIST). J Clin Oncol. 2005;23(16 Suppl):824S.

28. Kang Y, Reichardt P, Ruka W, Seddon B, Baum C, Demetri G. Efficacy and safety of sunitinib ina worldwide treatment-use trial of gist patients following imatinib failure. Ann Oncol. 2007;18 Suppl 7:vii16. Abstract O-0017.

29. Rankin C, von Mehren M, Blanke C, Benjamin R, Fletcher CDM, Bramwell V, et al. Dose effect of imatinib (IM) in patients (pts) with metastatic GIST-phase III Sarcoma Group Study S0033. J Clin Oncol. 2004;22(14S). Abstract 9005.

30. Reichardt P, Kang Y, Ruka W, Seddon B, Nieto A, Breazna A, et al. Sunitinib $(\mathrm{Su})$ in a worldwide treatment-use trial of patients with GIST: updated efficacy and safety analysis. Ann Oncol. 2008;19 Suppl 8:viii267. Abstract 869PD.

31. Reichardt P, Kang Y, Ruka W, Seddon B, Guerriero A, Breazna A, et al. Detailed analysis of survival and sfety with sunitinib (SU) in a worldwide treatment-use trial of patients with advanced GIST. J Clin Oncol. 2008;26(15 Suppl). Abstract 10548.

32. Rutkowski P, Reichardt P, Kang Y, Ruka W, Seddon B, Guerriero A, et al. Sunitinib in a worldwide treatment-use trial of patients with imatinib, resistant/intolerant gastrointestinal stromal tumor: detailed analysis of survival and safety. Ann Oncol. 2008;19 Suppl 6:vii12. Abstract O-013.
33. Schutte J, Reichardt P, Schlemmer M, Wendtner CM, Demetri GD. Efficacy and safety of sunitinib in patients with gastrointestinal stromal tumour resistant or intolerant of prior imatinib therapy: Results from a worldwide treatment-use study. Onkologie. 2008;31 suppl 1:77. Abstract OP130.

34. Seddon B, Reichardt P, Ruka W, Kang YK, Baum CM, Demetri GD. Safety and efficacy results of sunitinib from a worldwide treatment. use trial of gastrointestinal stromal tumour (GIST) patients (pts) with resistance or intolerance to prior imatinib therapy. Eur J Cancer Suppl. 2007;5(4):405. Abstract 7511.

35. Seddon B, Reichardt P, Kang YK, Ruka W, Nieto A, Breazna A, et al. Detailed anlaysis of survival and safety with Sunitinib in a worldwide treatment-use trial of patients with advanced imatinibresistant/intolerant GIST. Connective Tissue Oncology Society, 14th Annual Meeting, London, November 2008. Abstract 34980.

36. Zalcberg JR, Verweij J, Casali PG, Le Cesne A, Reichardt P, Blay JY, et al. Outcome of patients with advanced gastro-intestinal stromal tumors (GIST) crossing over to a daily imatinib dose of $800 \mathrm{mg}$ (HD) after progression on $400 \mathrm{mg}$ (LO)-an international, intergroup study of the EORTC, ISG and AGITG. J Clin Oncol. 2004;22(14S):9004.

37. An JY, Choi MG, Noh JH, Sohn TS, Kang WK, Park CK, et al. Gastric GIST: a single institutional retrospective experience with surgical treatment for primary disease. Eur J Surg Oncol. 2007;33:1030-5.

38. Chu TF, Rupnick MA, Kerkela R, Dallabrida SM, Zurakowski D, Nguyen L, et al. Cardiotoxicity associated with tyrosine kinase inhibitor sunitinib. Lancet. 2007;370:2011-9.

39. Goerres GW, Stupp R, Barghouth G, Hany TF, Pestalozzi B, Dizendorf E, et al. The value of PET, CT and in-line PET/CT in patients with gastrointestinal stromal tumours: long-term outcome of treatment with imatinib mesylate. Eur J Nucl Med Molecul Imag. 2005;32:153-62.

40. Nishida T, Shirao K, Sawaki A, Koseki M, Okamura T, Ohtsu A, et al. Efficacy and safety profile of imatinib mesylate (ST1571) in Japanese patients with advanced gastrointestinal stromal tumors: a phase II study (STI571B1202). Int J Clin Oncol. 2008;13:244-51.

41. Phongkitkarun S, Phaisanphrukkun C, Jatchavala J, Sirachainan E. Assessment of gastrointestinal stromal tumors with computed tomography following treatment with imatinib mesylate. World J Gastroenterol. 2008;14:892-8.

42. Pfizer Inc. Safety And Effectiveness Of Daily Dosing With Sunitinib Or Imatinib In Patients With Gastrointestinal Stromal Tumors. ClinicalTrials.gov Identifier NCT00372567. ClinicalTrials.gov; 2006 [accessed February 2011]. URL: http://clinicaltrials.gov/.

43. Demetri GD, Van Oosterom AT, Garrett CR, Blackstein ME, Shah MH, Verweij J, et al. Efficacy and safety of sunitinib in patients with advanced gastrointestinal stromal tumour after failure of imatinib: a randomised controlled trial. Lancet. 2006;368:1329-38.

44. Parmar MK, Torri V, Stewary L. Extracting summary statistics to perform meta-analyses of the published literature for survival endpoints. Stat Med. 1998;17:2815-34.

45. Arends LR, Hunink MG, Stijnen T. Meta-analysis of summary survival curve data. Stat Med. 2008;27:4381-96. 